\title{
Candidate Species for Florida Aquaculture: Evaluating an Aquatic Organism's Aquaculture Potential 1
}

Cortney L. Ohs and R. LeRoy Creswell ${ }^{2}$

\section{Candidate Species for Florida Aquaculture: Evaluating an Aquatic Organism's Aquaculture Potential}

This publication is the introduction to a series which will detail the potential of different aquatic organisms for aquaculture in Florida. This publication will define and describe important characteristics of aquatic species and discuss how these characteristics affect a species' aquaculture potential. It will serve as a summary of current knowledge, both known and unknown culture characteristics of a species, and will aid aquaculturists to make informed knowledgeable decisions. The known characteristics will be summarized by reviewing available scientific and extension literature. The unknown characteristics will clearly identify the research needs which must be addressed before recommendations can be made to potential producers on the species' aquaculture potential.

When evaluating the aquaculture potential of an aquatic species first check state laws on possessing, culturing, and marketing the product within the state and check federal laws if you plan to distribute to markets out of state. For further information on Florida laws and aquaculture see DACS (2005). For further information on interstate marketing see USFWS (2004).

If the species is legal to culture in your state and at your facility, then evaluate the culture potential for the species. Seek what information is already known about aquaculture of this species. When aquaculture information is lacking, you must evaluate several different characteristics including the natural history and ecology, dispersion, behavior, and its life stages. Then within each life stage, food preferences and range of water quality tolerances need to be defined. Finally, assess the market supply and demand, and the vulnerability of the organism to disease. All of this information should be collected before proceeding with a business plan for culturing a species.

\section{Natural History}

It is important to understand the natural history of the organism throughout its life stages in order to provide the optimal conditions for culture. Although

1. This document is FA146, one of a series, Candidate Species for Florida Aquaculture, http://edis.ifas.ufl.edu/TOPIC_SERIES_Candidate_Species of the Fisheries and Aquatic Sciences Department, Florida Cooperative Extension Service, Institute of Food and Agricultural Sciences, University of Florida. Original publication date June 15, 2007. Visit the EDIS Web Site at http://edis.ifas.ufl.edu.

2. Cortney L. Ohs, Assistant Professor, Indian River Research and Education Center, Department of Fisheries and Aquatic Sciences, 2199 South Rock Road, Fort Pierce, FL 34945. R. LeRoy Creswell, Marine Extension Agent, St. Lucie County Cooperative Extension, Fort Pierce, FL.

The Institute of Food and Agricultural Sciences (IFAS) is an Equal Opportunity Institution authorized to provide research, educational information and other services only to individuals and institutions that function with non-discrimination with respect to race, creed, color, religion, age, disability, sex, sexual orientation, marital status, national origin, political opinions or affiliations. U.S. Department of Agriculture, Cooperative Extension Service, University of Florida, IFAS, Florida A. \& M. University Cooperative Extension Program, and Boards of County Commissioners Cooperating. Larry Arrington, Dean 
the aquaculture environment does not mimic the natural environment of the cultured species (e.g., stocking density, feeding), any information that provides the optimal environmental conditions of the species should establish the appropriate culture conditions (e.g., water quality, light cycle and intensity) for the various life stages. Most of the needed information on the natural history of an organism is available in the scientific literature. However, this information has not been summarized with an aquaculture perspective.

\section{Culture Techniques}

The environmental conditions and culture methods will vary widely between species and also between life stages of individual species. Again, the natural history of the species will provide important insights into the culture conditions for each life stage. The culture techniques and conditions will be dictated by the natural history of the organism during all the life stages. Generally the culture techniques are divided into broodstock, hatchery, nursery, and growout stages. Each stage will be addressed separately in the following.

\section{Broodstock}

Broodstock is the term used to identify the parent stock of the cultured species. Broodstock acquired from the wild should be quarantined for a period of time sufficient to ensure that no parasites or pathogens are introduced into the culture environment. This may involve disease screening by aquatic veterinarians and using chemical treatments to ensure the brood are parasite and pathogen free. For more information on quarantine techniques to prevent pathogen introduction for broodstock see EDIS FA099, FA100, and FA101. When broodstock arise from previous culture cycles it is less critical to quarantine them because the pathogens may already be present but have not manifested in a disease. Proper handling of the broodstock is important to prevent stress and depressed immunity, thus handling broodstock fish typically occurs after anesthetizing them with either tricaine (tricaine methanesulfate, MS-222, Tricaine-S, and Meta-caine), Eugenol, Iso-eugenol, quinaldine, or metomadate. The choice of anesthetic will depend on species and associated laws. The use of anesthetics is discussed in IVIS Document No. A1412.0701.

Artificial spawning techniques simulate natural pre-spawn changes in the environment, usually temperature, photoperiod, and/or salinity manipulation. These changes may initiate spawning activity but the frequency can be highly variable within individuals in the entire population. Therefore, in many fish species various hormones are used to synchronize spawning activity of the entire population. This is necessary for efficient management of a hatchery because a sufficient population of larvae is necessary at one time to justify the time and expense to culture. Hormones are commonly injected or a time release implant is used. For further information on the use of spawning hormones used for fish see SRAC 421-426.

\section{Hatchery}

Once the broodstock have spawned the hatchery stage begins. Since eggs are fertilized and incubated in many different ways in nature, the aquaculturist should make every effort to duplicate natural conditions.

During natural spawning events eggs are broadcast, laid on various substrates, or hatched as larvae (live bearers). Broadcast spawners distribute eggs into the water column and are fertilized in the tanks. Commonly, fertilized eggs are concentrated in specifically designed egg collectors. The eggs are then removed and incubated until hatching. Some aquatic species naturally lay and fertilize their eggs on or in objects; aquaculturists provide artificial substrates for spawning which mimic their natural spawning site preferences. This allows the fertilized egg masses to be moved into other tanks or ponds before hatching. With live bearers either the parents or larvae are removed and placed into another tank or pond. For more information on methods for incubating eggs see EDIS FA051.

Many cultured fish species require eggs to be artificially spawned, known as strip spawning, a process in which the culturist physically removes eggs and sperm from the parents to coincide the brood population's spawning activity. This allows for more eggs to be produced at any one time. In this 
case the eggs are artificially fertilized by mixing eggs and milt in a bowl and then incubating the fertilized eggs in hatching jars or specialized tanks.

For all species of aquatic organisms there is a larval stage requiring a controlled environment, thus all water quality parameters should closely duplicate that of the natural environment. For some species the methods to successfully hatch eggs and culture larvae are unknown, while culturing larvae of other species is impractical because of required live feed organisms or the length of the larval cycle. In these cases, larvae or juveniles are often collected from the wild.

\section{Nursery}

The nursery stage begins when the organism is large enough that some developmental change has occurred which signifies it is no longer a larva, often called "metamorphosis", "setting", or "transition" in the scientific literature. This could be a change in morphology (physical appearance), food preference, or habitat preference. When culturing a juvenile aquatic species the environmental conditions of the culture system should be consistent with what the animals would experience in their natural environment. At some point during the juvenile stage, aquatic species with the best aquaculture potential become capable of consuming artificial formulated and commercially available particulate diets. Fishes with the greatest potential for aquaculture are those that can be weaned to commercially available feeds early in their juvenile stage. In order for an artificial diet to be provided, a weaning process is instituted as the cultured organism's diet is shifted from an exclusive live food to an exclusive artificial formulation. This is termed feed training, and the process and the age when the organism is capable of this diet change varies between species.

In contrast, bivalve mollusks, such as oysters, clams, mussels, and scallops, are filter feeders and filter phytoplankton from the water. Production of live phytoplankton is a cost prohibitive process, and most bivalves are transferred after the nursery phase to the natural environment to provide sufficient food resources to grow to a marketable size. In Florida, this requires obtaining leased submerged lands from the state that have been certified for shellfish culture and are subject to state regulation. For further information see DACS (2005).

Other organisms such as corals, anemones, sponges, and some species of clams are symbiotic hosts to algae living within their cells which harvest sunlight and create food for the host organism. These species require little or no supplemental food.

\section{Growout}

The "growout" phase in aquaculture is defined as the time period from when an organism is transferred from the nursery environment until it is harvested for market. The growout phase typically involves an increase in feed rations, size grading and distribution of animals to maintain optimal stocking density, and more rigorous monitoring of water quality and other environmental parameters. The size of a cultured species for harvest is a business consideration based on growth rate, market demand, and production costs. Other important considerations are the systems necessary to culture the species (tanks, ponds, or cages), power and labor costs, harvesting, processing, and transport of the product. This will have a major impact on the cost of production per unit. Another important consideration is the feed conversion ratio (FCR) or the efficiency the organism converts the consumed feed into mass. Since feed is often the largest variable cost, the efficiency with which the organism converts feed is critical for the economic success of an aquaculture operation.

\section{Market}

Marketing is one of the most important considerations for a producer; many producers successfully culture organisms to market size without identifying the critical issues of supply and demand that will ultimately determine their profitability. Marketing opportunities will change with location, season, demographics, and advertising and branding efforts. For marketing to distant locations transportation costs must be considered. For example, marketing exclusively to buyers in proximity to the farm may be more profitable than shipping to more distant markets that will pay more for the same product after accounting for shipping and distribution costs. 
Also, it is critical to identify your competition for the available market. Imported products, either the same species or similar, must be considered because usually an imported product's wholesale price is much lower than the production costs for products cultured in the United States, and both are supplying the same market demand. Niche markets are available for some cultured aquatic organisms and often provide a producer the highest market price available, but their size may be a limiting factor. It is important for an aquaculturist in the U.S. to put extensive effort into supplying and expanding niche markets and scheduling his or her production schedule to cater to these customers. Marketing costs, such as brokering fees, packaging and distribution costs, labor, and advertising, must also be taken into account and are part of the total production costs. For more information on marketing aquaculture products see SRAC 350.

\section{Disease}

All organisms are susceptible to various pathogens and parasites during their life. Healthy organisms often carry opportunistic pathogens; the stressful conditions of an aquaculture environment can cause these pathogens to proliferate and manifest themselves as diseases. As such, the most successful aquaculture species are generally more resistant to stress in the culture environment and less likely to develop disease. If disease symptoms are present, there are treatments specific to the pathogen and the cultured species under treatment. However, application of disease treatments for cultured organisms is highly regulated, especially for those organisms which are cultured for human consumption. Rules, treatment methods, vulnerability, and costs to treat potential disease outbreaks need to be considered before culturing an organism because this can have a profound impact on the margin between cost of production and market price. For further information on pathogens of aquatic organisms and treatment see EDIS FA-004.

\section{Conclusion}

This publication has summarized the critical issues aquaculturists should consider before attempting to culture an aquatic species to sell for profit. A successful aquaculturist will consider all of these issues when developing an aquaculture business plan.

This publication is the introduction to a series of EDIS publications. Each publication to follow will summarize the current knowledge of these critical characteristics for aquatic species which are of interest or have the potential as a species for aquaculture in Florida.

\section{Characteristics to evaluate when considering the aquaculture potential for a species.}

1. Legally cultured

2. Biology, ecology, and life history known

3. Culture methods known

4. Perceived market value

5. Supply and demand

6. Availability of broodstock or larvae

7. Ability to culture at high population densities in a controlled environment

8. Ability to consume and efficiently grow on artificial formulated diets

9. Able to mimic natural life cycle in a controlled environment

10. Possibility of captive breeding and closing the life cycle in a controlled environment

11. Market size is attainable in economically feasible period of time

12. Minimal vulnerability to pathogens

\section{Recommended Reading}

DACS. 2005. Aquaculture Best Management Practices Manual. Florida Department of Agriculture and Consumer Services, Division of Aquaculture, Tallahassee, FL. http://www.floridaaquaculture.com/Pub.htm 
International Veterinary Information Service

Document No. A1412.0701. Anesthetic Options for Fish.

http://www.ivis.org/advances/Anesthesia_Gleed/ bowser/ivis.pdf

SRAC 350 Small scale marketing of aquaculture products. Available at http://srac.tamu.edu

SRAC 421 Introduction to Hormone-Induced Spawning of Fish. Available at http://srac.tamu.edu

SRAC 422 Capturing, Handling, Transporting, Injecting and Holding Brood Fish. Available at http://srac.tamu.edu

SRAC 423 Determining Sexual Maturity of Broodstock for Induced Spawning of Fish. Available at http://srac.tamu.edu

SRAC 424 Hormonal Control of Reproduction in Fish for Induced Spawning. Available at http://srac.tamu.edu

SRAC 425 Hormone Preparation, Dosage Calculation, and Injection Techniques. Available at http://srac.tamu.edu

SRAC 426 Techniques for Taking and Fertilizing the Spawn of Fish. Available at http://srac.tamu.edu

SRAC 700 Zooplankton Succession and Larval Fish Culture in Freshwater Ponds. Available at http://srac.tamu.edu

SRAC 701 Culture of Small Zooplankters for the Feeding of Larval Fish. Available at http://srac.tamu.edu

SRAC 702 Artemia Production for Marine Larval Fish Culture. Available at http://srac.tamu.edu

UF/IFAS Fact sheet FA-004. Introduction to fish health management. http://edis.ifas.ufl.edu/FA004

UF/IFAS Fact sheet FA-121. Regulations pertaining to non-native fish in Florida aquaculture. http://edis.ifas.ufl.edu/FA121
UF/IFAS Circular 120 Fish Health Management Considerations in Recirculating Aquaculture Systems - Part 1: Introduction and General Principles. http://edis.ifas.ufl.edu/FA099

UF/IFAS Circular 121 Fish Health Management Considerations in Recirculating Aquaculture Systems - Part 2: Pathogens. http://edis.ifas.ufl.edu/FA100

UF/IFAS Circular 122 Fish Health Management Considerations in Recirculating Aquaculture Systems - Part 3: General Recommendations and Problem-Solving Approaches. http://edis.ifas.ufl.edu/FA101

USFWS. 2004. Importing and Exporting Your Commercial Wildlife Shipment. U.S. Fish and Wildlife Service, Office of Law Enforcement, Arlington, VA.

http://www.fws.gov/le/ImpExp/

CommWildlifeImportExport.htm 